\title{
Raising the bar
}

\author{
Thomas L. Slovis • Guy Sebag
}

Received: 5 August 2010/Accepted: 7 August 2010

(C) Springer-Verlag 2010

The members of our societies have voiced enthusiasm about the journal's many changes. In recent years, we have added reviews, pictorial essays, minisymposia, supplements, Hermes, Exposure and clinical images, while keeping to our goal of publishing original research and technical progress in our field. In the August issue, we added point/counterpoint and eventually plan a new feature called Clinical Corner. The reviews, minisymposia and original articles have been quite well cited, and our longevity of citations (5-year impact factor is greater than 1 year) and frequency of citations have given us the 5th highest Eigenfactor score among the subspecialty radiology journals cited [1]. The Eigenfactor is a metric that takes into account the quality of the citing journals as well as the quantity of citations [2].

We also publish case reports. Many of our readers and authors continue to comment on the positive value of case reports. Some readers and authors believe we are not getting more original research because of our impact factor. What is the impact factor? It is a standard derived by the Institute of Scientific Information (ISI), which rates journals (with a 2year lag time) on the number of citations/articles published. Whether we like it or not, many European universities demand that their faculty submits to journals with a higher impact factor than Pediatric Radiology's in order for those publica-

\section{T. L. Slovis $(\square)$}

Department of Pediatric Imaging,

Children's Hospital of Michigan,

3901 Beaubien Blvd.,

Detroit, MI 48201, USA

e-mail: pedradeditor@med.wayne.edu

G. Sebag

Service d'Imagerie Pédiatrique, Hôpital Robert Debré,

Paris, France tions to count toward promotion. The value of the impact factor has been debated. Lee Rogers, former editor of AJR, said journals that only publish reviews are most highly rated, but may never present anything original [3]. AJR and Radiology no longer publish case reports.

The managing editors feel strongly that good case reports add to our knowledge, help us in our clinical work and are valuable. After several years of discussion at Editorial Board meetings in the U.S. and Europe on what role the impact factor should have on our journal, we decided on a compromise. Beginning in January 2011, we will stop publishing clinical images. These articles have generated little in the way of citations. Many of the images would be valuable as case-of-the-day items on our societies' Web sites.

We will continue to publish case reports, albeit fewer of them than in prior years. We are raising the bar. Case reports must have clinical ramification, either to other diseases or to the diagnosis and/or management of the disease presented. The discussion must be cogent and prescient. Pathological proof, when appropriate, is recommended.

To expedite this change, we will publish a supplement in December 2010 of all accepted clinical images and most of the accepted case reports. We will stop accepting clinical images with publication of this editorial. Our goal is to give our readers the material they value, while respecting the needs of all. This, hopefully, will lead us to a win-win decision.

\section{References}

1. Durieux V, Gevenois PA (2010) Bibliometric indicators: quality measurement of scientific publication. Radiology 255:342-351

2. Bergstrom CT, West JD, Wiseman MA (2008) The Eigenfactor metrics. J Neurosci 28:11433-11434

3. Rogers LF (2002) Impact factor: the numbers game. AJR 178:541542 